\title{
Primary ovarian leiomyosarcoma: a case report with review
}

\author{
Jasmeen Kaur $^{1 *}$, Megha Mishra ${ }^{2}$, Bharti Goel ${ }^{1}$ \\ ${ }^{1}$ Department of Obstetrics \& Gynecology, Government Medical College and Hospital, Chandigarh, Punjab, India \\ ${ }^{2}$ Department of Obstetrics \& Gynecology, Consultant Patel Hospital, Jalandhar, Punjab, India
}

Received: 18 December 2013

Accepted: 06 January 2014

*Correspondence:

Dr. Jasmeen Kaur,

E-mail: drjasmeen81@yahoo.in

(C) 2014 Kaur J et al. This is an open-access article distributed under the terms of the Creative Commons Attribution

Non-Commercial License, which permits unrestricted non-commercial use, distribution, and reproduction in any medium, provided the original work is properly cited.

\section{ABSTRACT}

Primary ovarian leiomyosarcoma is a very rare tumor. Presenting a case report with review of literature.

Keywords: Primary ovarian leiomyosarcoma, Leiomyosarcoma, Primary ovarian

\section{INTRODUCTION}

Primary ovarian leiomyosarcoma is very rare ovarian tumor, with less than 50 cases in the literature. ${ }^{1}$ Because of its extreme rarity; a standard treatment isn't yet established. We present this case of ovarian neoplasm in a postmenopausal woman. Literature of primary leiomyosarcoma of the ovary is reviewed.

\section{CASE REPORT}

A 59 year old female, $\mathrm{P}_{2} \mathrm{~L}_{2} \mathrm{~A}_{1}$ came with complains of post-menopausal bleeding since 1 week, it was mild in amount; there was no history of contact bleeding. No complains of pain abdomen or any urinary complains.

On per abdomen examination, abdomen was soft, no guarding, rigidity or tenderness was present. On per speculum examination cervix appeared to be healthy, bleeding was seen through the os. On per vaginal examination multiparous anteverted uterus palpable, a 3 by $4 \mathrm{~cm}$ mass was palpable in right fornix, left fornix was free and non-tender.

Routine investigations were normal. CA-125 was $5.5 \mathrm{U} / \mathrm{ml}$. On ultrasonography, anteverted uterus with thick ET of $13 \mathrm{~mm}$ was noted; a4 by $4 \mathrm{~cm}$ solid right adnexal mass was seen, likely to be of ovarian origin, normal left ovary seen. On MRI pelvis solid right ovarian mass likely neoplastic, showing internal cystic changes.
Thick ET with poor definition of cervico vaginal junction, suggestive of endometrial hyperplasia/ endometrial carcinoma. No obvious ascites or deposits on serosal surface of pelvis, no enlarged lymph nodes noted. On Fractional Curettage findings were suggestive of simple endometrial hyperplasia along with chronic cervicitis. Ultrasound guided FNAC of the mass showed blood component with occasional cluster of epithelial cells having mild atypia, aspirate was inadequate for a definitive opinion.

On laparotomy, TAH with BSO was done. On imprint cytology of right ovary, it was found to be benign ovarian tumor. On histopathology? Cellular fibroma? fibrosarcoma. On immunohistochemistry, intermediate grade leiomyosarcoma was diagnosed. Microscopic examination of left ovary revealed normal ovarian stoma. No leiomyoma were detected in sections taken from uterus and tubes.

\section{DISCUSSION}

Primary ovarian sarcoma are very rare tumors, comprising less than $2 \%$ of all ovarian malignancies. ${ }^{1}$ They are a heterogeneous group of tumors, consisting of the fibrosarcomas, endometrial stromal sarcomas,rhabdomyosarcoma ${ }^{3,4}$ and the rare leiomyosarcomas, ( less than $0.1 \%$ ). ${ }^{1}$ 
Primary ovarian leiomyosarcomas are usually seen in postmenopausal women, though few cases seen in younger women have been reported. ${ }^{1,3}$ Ppathogenesis of ovarian leiomyosarcomas is not clear, though various theories proposed, two of the prominent ones being, malignant degeneration of smooth muscle tissue present in the ovary and malignant transformation of uterine leiomyoma to the ovary. ${ }^{4}$ Leiomyomas are usually seen in superficial tissue, where as leiomyosarcomas are deep seated tumors, ${ }^{6}$ thus negating the theory of leiomyomas to be the precursor of leiomyosarcoma.

According to the source of origin, ovarian leiomyosarcomas can be divided into three types, teratoid, mesenchymal and mullerian. ${ }^{7}$ Leiomyosarcomas of teratoid origin are usually unilateral and observed in young patients where as those of mesenchymal origin are seen more commonly in the elderly age group and more likely to metastasize.

Leiomyosarcomas usually present late with vague nonspecific symptoms comprising of vaginal bleeding, pelvic pain or pressure, urinary or bowel complaints and awareness of abdomino pelvic mass which is on examination is appears as a unilateral, solitary, soft and fleshy mass.

On pathological examination, grossly they are indistinguishable from other sarcomas and appear as solid masses with or without cystic degeneration, depending on size of tumor. ${ }^{2}$ Microscopically, uniform spindle shaped cells with abundant eosinophilic cytoplasm and elongated nuclei are seen. They are arranged in whorled pattern with areas of pleomorphism and necrosis. ${ }^{3}$ They differ from the leiomyomas in being hypercellular and having increased mitotic activity (10 or more mitoses per 10 hpf). ${ }^{3}$ Coagulative necrosis, cellular atypia and mitotic index greater than 10 are taken to be evidence of malignancy. Immunohistochemical and electron microscopic evaluations may improve diagnostic accuracy.

Due to rarity of the disease and late presentation, a standard optimal treatment does not exist.Different treatment modules have been described in literature. Postoperative radiotherapy and chemotherapy have been recommended in large tumours to prevent local and metastatic spread of the disease. ${ }^{2}$ In a study by Rasmussen et al. ${ }^{3}$ treatment with repeated cyto-reductive surgery, hormonal treatment and adjuvant ifosfamide has shown to have better prognosis than surgery alone. Pre operative chemotherapy has also been tried in large tumors to increase chances of operative success. Still there is no conclusive evidence that adjuvant chemotherapy or radiotherapy offers prognostic benefit and surgery has remained the mainstay of treatment. ${ }^{2}$ Ploration. 9

Ovarian leiomyosarcomas have poor prognosis and patients usually due to their late presentation and aggressive nature. Patients usually expire within one year, ${ }^{4}$ because of late presentation and aggressive nature of the tumor leading to widespread metastasis and pressure symptoms from the large ovarian tumor.

In our patient radical surgery wasn't done because, imprint cytology suggested a benign ovarian tumor and omentectomy/ omental biopsy / lymphadenectomy was also not done. Post operatively under supervision of oncologist patient is on repeated CT every 6 months. Patient is asymptomatic and healthy. Probably surgical intervention at an early stage has helped in improving her prognosis. Moreover, considering the age of the patient and rarity of a benign tumor at this age, in spite of imprint cytology, she could have been given the benefit of doubt and omental biopsy / lymph node biopsy / peritoneal washings could have been taken.

\section{CONCLUSIONS}

Ovarian leiomyosarcomas are very rare ovarian tumors, whose origin is unclear. They are very aggressive tumors with poor prognosis. Optimal debulking surgery has prognostic value in the course of disease. There is need for further research in efficacy of adjuvant chemotherapy, radiotherapy.

\section{Funding: No funding sources Conflict of interest: None declared Ethical approval: Not required}

\section{REFERENCES}

1. Bouie SM, Cracchiolo B, Heller D. Epithelioidleiomyosarcoma of the ovary. Gynecologic Oncology. 2005;97:697-9.

2. Rosai J. Female reproductive system, ovary. In: eds. Ackerman's Surgical Pathology. 7th ed Washington DC: CV Mosby Co; 1989: 1163.

3. Friedman HD, Mazur M. Primary ovarian leiomyosarcoma. An immuno-histochemical and ultrastructural study. Arch Pathol Lab Med. 1991;115:941-5.

4. Kurian RR, Preethi J, Remadevi AV. Leiomyosarcoma of ovary - a case report. Indian J Pathol Microbiol. 2005;48:19-20.

5. Enzinger FM, Weiss SW. Soft Tissue Sarcoma. In: eds. 2nd ed. Washington DC: The CV Mosby Co; 1988: 402.

6. Azoury RS, Woodruff X. Primary ovarian sarcoma. Obstet Gynaecol. 1971;37:920-41.

7. Prat J, Fox H. Mesenchymal tumour of the ovary In: Fox H, eds. Hainjps and Taylor Obstetrics and Gynaecology. 2nd ed. Edinburgh: Churchill Livingstone; 1987: 701.

8. Russel P, Banntype P, Solomen HJ. Malignant Mullerian and miscellaneous mesenchymal tumours of the ovary. In: Copplesonn M, eds. Gynaecologic Oncology. 2nd ed. Edinburgh: Churchill Livingstone; 1992: 971. 
9. World Health Organization. Handbook for reporting results of cancer treatment. Geneva: World Health Organization, $1979 . \quad$ Available at: whqlibdoc.who.int/offset/WHO_OFFSET_48.pdf.

10. Dixit S, Singhal S, Baboo HA, Vyas RK, Neema JP, Murthy R, Sooryanaraya U. Leiomyosarcoma of the ovary. J Postgrad Med. 1993;39(3):151-3.

11. Rasmussen CC, Skilling JS, Sorosky JI, Lager DJ, Buller RE. Stage IIIC ovarian leiomyosarcoma in a premenopausal woman with multiple recurrences: prolonged survival with surgical therapy. Gynecol Oncol. 1997;66(3):519-25.
12. Istre BJ. Sarcoma of the ovary. J Oslo City Hosp. 1951;10:231-3.

13. Shakfeh SM, Woodruff JD. Primary Ovarian sarcoma, report of 46 cases and review of literature. Obstet Gynecol Survey. 1987;42:331-49.

DOI: $10.5455 / 2320-1770$. ijrcog20140355

Cite this article as: Kaur J, Mishra M, Goel B.

Primary ovarian leiomyosarcoma: a case report with review. Int J Reprod Contracept Obstet Gynecol 2014;3:258-60. 